\title{
LA HISTORIA UNIVERSAL COMO HISTORIA MORAL DEL GÉNERO HUMANO EN JOVELLANOS*
}

\author{
Fernando BARAS ESCOLA
}

«La historia ... presenta [al fitósofo] en augusta perspectiva, con las verdades y los errores, y las virtudes y los vicios de todos los siglos, aquella rápida vicisitud con que la etema Providencia levanta los imperios y naciones, y los abate y los rae de la faz de la tierra. Y si en este magnífico teatro ve al mayor número de los hombres arrastrados por la anbición y la codicia, también lo consuelan aquellos pocos modelos de virtud que descuellan acá y allá en el campo de la historia, como en un bosque devorado por las llanas, tal cual roble salvado del incendio por su misma proceridads.

(G. M. de JOVELLANOS, Oración sobre la necesidad de unir el estudio de la literatura al de las ciencias, 1797)

* Siglas y abreviaturas utilizadas: AHV = Archivo Historico Nacionai. ARAH = Archivo de la Real Academia de la Historia. BAE = Biblioteca de Autores Espanoles. BI-Li = Bulletin Hispanique. $\mathrm{EHS}=$ Estudios de Historia Social. NRFH = Nueva Revista de Filología Hispánica. $(O)(C=$ Obras Completas de Jovellanos (erl, de José Miguel Caso).

I Los títulos completos de las obras generales de Jovellanos que apacecen en el texto con las abreviaturas BAE y OOCO son los siguientes: BAE T. XLVI y L: Obras publecadas e incélitas de D. Gaspar Melchor de Jovellanos. Colección hecha e ilustrada por D. Cándido Nocedal. Madrid, 1865 (reed. en 1963 y 1952). BAE T'. LXXXV-LXXXV II: Ohras publicades c inéditas de D. Gaspar Melchor de Jovellnnos, Edición y estudio preliminar de Miguel Artok. Madrid, 1956-1959. OOCO T. II: Gaspar Melchor de Jovellanos, Obras campletes. Tomo H. Correspondencia. 1. ${ }^{\circ}$ (1767-Junio 1794). Edición crícat, introducción y notas de José Miguel Caso Gonzátez. Oviedo/Cijon, 1985. OOCC Т. III: Obras completas. Tomo III. Coryespondencira. 2. (Julio 1794-Marzo 1801). Exticion crítica, introducción y notas de Jasé Migtrel Caso Gonzátez. Oviedo/Gijón, 1986. OOCC t. v.: Obras completas. Tomo $V$. Comespondencia fu foctubre, 1508-1811) (Adidenda). Edición crítica, introducción y notus de José Miguel Cern González. Oviedo/Cijón, 1990. 
La dimensión ecuménica de la "historia moral», disciplina que debe más a la reflexión filosófica que a la erudición, se configura como postulado clave de la ideología ilustrada. La *historia moral» de la cultura busca en el pasado arquetipos de comportamiento social y, aunque no tiene por qué oponerse en principio a la historia «crítica», «filosófica» y «civil»', goza de plena autonomía epistemológica como dominio intelectual. En cierto sentido, la «historia moral» cumple una función análoga al pensamiento utópico, pues su objetivo no consiste en la reconstrucción del pasado sino en la comparación de modelos ideales de civilización, para descubrir las contradicciones de fondo sobre las que reposa la sociedad del momento, con la diferencia -claro está- de que la «historia moral» aspira a explicar el curso evolutivo de los modelos que describe.

\section{Escribe Ronsseau en 1740:}

"C"est alors que je tacher'ai de lui en faire tirer tout le profit qu'on peut espérèr de cette étude, et de lui faire distinguer le génie et les moeurs des différentes nations, leur's vices et leurs verturs, les cuuses de leur's progrès tet de lcurs désadences, les grands hommes qu'elles ont produits et les caractères des différents historiens ${ }^{2}$.

Iin Jovellanos la shistoria moral» se inicia con la imagen de la civilización greco-romana, mediatizada por el tópico neoclásico. Grecia y Roma contienen las «fuentes purísimas» y los «grandes modelos» del universo literario de todas las époras:

eNo hay antre nosotros, no hay todavía en ninguna de las naciones sabias cosa comparable a Homero y Píndaro, ni a Horatio y el Mantuano; nada que iguale a Jenofonte y Tito Livio, ni a Demóstenes y Cícrón. Pero, j̇de dónde. viene esta vergonzosa diferencia? ¿Por qué en las obres de los modernos, con más sabiduría, se halla menos genio que en las de los antiguos, y por qué briIlan más los que supieron menos? La razón es clara, dice un moderno: porque los antiguos estudiaron en la naturaleza y nosotros en ellos. ¿Por qué, pues, no estudiaremos como ellos? He aquí en lo que debemos initarlos ${ }^{3}$.

Al igual que Rousseau, Jovellanos contempla la antigïedad clásica como la edad en la que el hombre vive más próxino a los objetos de la naturaleza y que-

Solbre la listoria *erítica*, *filosófica y acivil en Jovellanos ver Fernando BARAS, Gaspas Aclchor de Jovellanos (1744-1811). Una biografia intelectual. (Reformismo político y revolución ideológicu). Tesis doctoral inédita leída en Zaragoza en 1991, ff. 501-528.

2 Jean-Jacques ROUSSEAU, Mémoire à Mably sur léducalion de son fils (1740). Git. en Marc EIGELDINGER, "La vision de l'histoixe dans l'Emile*. En: L'Histoire aut dix-huiriene siecle. Aix-en-Provence, 1980, pág. 430.

3 G. M. de JOVELLANOS, Onación sobre la necesidad de mir el esfudio de la literatura al de las ciencias (24-IV-1797), en BAET. XLVI, pág, 331b-332a. 
da más fuertemente impresionado por cuanto le rodea. El hombre moderno del siglo XVIII, por el contrario, parece atrapado en una cultura libresca que apenas filtra el elemento natural. En aquel perdido paraíso de la libre creación el filósofo tenía a la vista una naturaleza sugestiva y sin mediaciones, porque su misma inspiración era por completo original. De ahí que Jovellanos advierta una superioridad incuestionable de los clásicos sobre el "rebaño de metodistas y copiadores», y recomiende a sus coetáneos que se apliquen "más a la observación y a la meditación que a una infructuosa lectura ${ }^{*}$. En el Curso de humanidades castellanas de 1794, refiriéndose al «estilo patético y vehemente» afirma:

*El ingenio ni el arte en esta ocasión no pueden suplir el sentiniento, porque el que no ha probado una pasión ignora su idioma, y sólo muy imperfectamente se la puede enseñar el arte. Las pasiones deben ser miradas como la semilla productiva de los grandes pensamientos; ellas son las que mantienen una perpetua fermentación en nuestras ideas y fecundan en la imaginación las que serían estériles en un alma tibia ${ }^{5}$.

Y más adelante, tras sentar el principio de que «la verdadera elocuencia no es otra cosa que la efusión de un alma sencilla, sensible y juntamente grande», ofrece este consejo:

«Es preciso precavemos ... de la imitación servil de un autor, cualquiera que sea. Esto siempre es dañoso, porģue embota el genio y fácilmente hace resbalar en una manera dura; y los que se dan a una imitación rigurosa, del mismo modo imitan los defectos del autor que las bellezas. Ninguno será buen escritor u orador sin seguir con alguna confianza su genios.

Pero, si la ventaja de los antiguos no deriva de la razón, sino de una especial disposición de las facultades anímicas, la imitación de su actitud conlleva necesariamente un proyecto de educación de la conciencia (del a alma», como la denomina Jovellanos). Es la propia condición humana la que regula la sensibilidad artística de los pueblos. La crítica estética se transforma en crítica moral:

«Juzgad [a los grandes talentos de la Antigüedad] no ya por lo que supieron y dijeron, sino por lo que hicieron, y veréis de cuánto aprecio no son dignos unos hombres que parecían nacidos para todas las profesiones y todos los empleos $\%$ ?.

Los grandes modelos a los que alude la cita son personajes de la talla de Pericles, Cicerón, César o Plinio, hombres que combinaron la política con las

+ Ibid., pág. 332a.

- G. M. de JOVELLANOS, Curso de Humanidades Castellanas (13-VII-1794), en BAET. XLVI, pág. 128a. N.B.: No es del todo segura la paternidad jovellanista de este texto.

Ibid., pág. $128 \mathrm{a}-\mathrm{b}$ y $130 \mathrm{~b}$.

G. M. de JOVELLANOS, Oración sobre la necesidud, pág. 332a. 
letras, el gobierno con la elocuencia, la magistratura con el cultivo de las ciencias. Su carácter ejemplar reside justamente en esa multiplicidad de facetas en que se dispersa la energía vital del «genio». Lo que atrae a Jovellanos de la cultura clásica no es otra cosa que la voluntad de dominio político-intelectual de una minoría. El hombre culto de la modernidad debe asimilar tal actitud expansiva comprometiéndose activamente con la práctica ilustrada:

"Consagrado al servicio público, jcon cuánto esplendor no llenará las funciones que le confiere la patria? Mientras las ciencias ... le hagan ver en todi su luz los objetos del público interés que debe promover y los medios de alcanzarlos .... la literatura le allanará las sendas del mando. Dirigiendo o pxhortando, hablando o escribiendo, sus palabras serán siempre fortificadas por la razón o endulzadas por ta clocuencia, y excitando los sentimientos y cap-

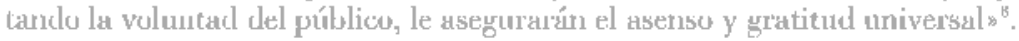

Arrebatado por la vehemencia de su discurso ético, Jovellanos obsequia a los, suponennos, atónitos oyentes del Instituto de Náutica con un párrafo como el anterior acerca de las cualidades directivas del político «ilustrado», lo que no tiene la menor relación con el futuro que aguarda a los alumnos que le escuchan, fin el mismo texto presenta la antítesis de la actiud clásica frente a la vida y la personifica en «uno de aquellos sabios especulativos», descrito en rápido apuntc como sabstracto en los principios», "taciturno» y entregado a «nocturnss Jucubraciones». Fste personaje carece del mímimo sentimiento de solidaridad "patriótica», es un parásito, un "enemigo de la sociedad»".

Pero, ¿hasta dónde llegá el mimetismo moral del ilustrado con respecto al arquetipo chásico? Allí donde empieza el mensaje de Cristo termina la doctrina de los moralistas profanos. En la Antigüedad, dice Jovellanos a sus discípulos del Institutio,

*... encontraréis aquella moral purisima que profesaron los hombres virtuosos de todos los siglos, que después ilustró, perfeccionó y santificó el Evangeclio, y que es la cinne y ciniento de nuestra rugasta religión. (...) Las oloras de Platón y Epicteto, las de Cicerón y Séneca, ilustrarán vuestro espíritu e inflarán vuestro cornzón. Nupstra religión sacrosauta elevará vuestras ideas, os

" Mrid., prig. 333at.

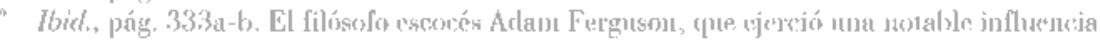

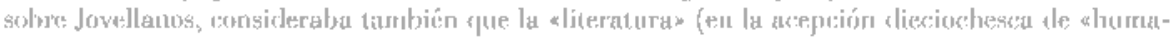
nidarless) debia ser a help to out conduct, and the means of forming a character that may be happy

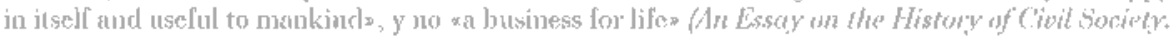

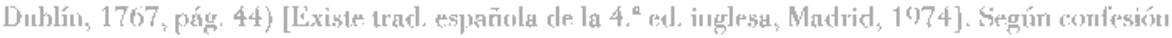

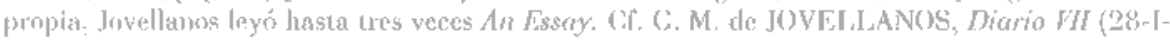

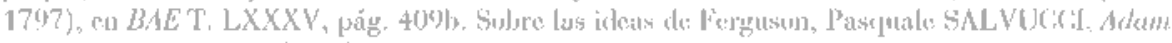

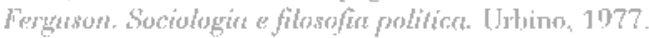


dará ... la justicia de principios y de sentimientos que caracterizan la virtud verdadera ${ }^{10}$.

El perfeccionamiento espiritual del género humano se concibe como un proceso que, iniciado en Grecia y Roma, tiene su culminación axiológica en la religión cristiana, cuya misión histórica no habría consistido en revocar los grandes principios de aquella moral que "profesaron los hombres virtuosos de todos los siglos», sino en conferirle una extensión y una hondura hasta entonces desconocidas. Jovellanos sigue en este punto la formulación que avanzaba Turgot en Tableau des progrès de l'esprit humain:

«Religion sainte, pourrais-je vous oublier? Pourrais-je oublier les moeurs perfectionnées, les ténèbres de l'idolatrie enfin dissipées, les hommes éclairés sur la divinité? (...) Quand l'Europe fut la proie des barbares, vous seule apprivoisates leur férocité» ${ }^{11}$.

El papel de la Iglesia se ensalza, no en cuanto comunidad de los creyentes, sino por su contribución a la resolución de los conflictos esenciales de la sociedad. El problema de la relación entre religión y razón se plantea en unos términos estrictamente pragmáticos, esto es, en el terreno de una discusión político-moral. Si a la razón le otorga Jovellanos un valor positivo al reconocer en ella un componente imprescindible de la felicidad humana ${ }^{12}$, a la religión la juzga de modo favorable en la medida en que mejora las «costumbres» y permite el progreso material y espiritual de la Humanidad:

aCon todo, se ha sentado por principio que las leyes no deben ser más perfectas de lo que los hombres en su estado pueden sobrellevar. Como si la legislación de J. C. no se dirigiese a perfeccionar el género humano y como si para perfeccionarlo hubiese temporizado con la corrupción de Roma que Petronio, Suetonio, Juvenal y Tácito describen, o con la de otros pueblos, y aun del judaico que Josefo pinta. ¿̨No se debe a esta ley de perfección que la Eu-

10 G. M. de JOVELLANOS, Oración sobre la necesidad, pág. $334 \mathrm{a}$.

1 Anne-Robert Jacgues TURGOT, Tableau philosophique des progrès successifs de lesprit humain (1750). En: Érits économiques. París, 1970, pág. 53. [Existe trad. española del Tableau y otros textos de Turgot con el título El progreso en la Historia Universal. Madrid, 1941, pág. 35 39). Ciaudio SIGNORILE lıa analizado recientemente la relación que establecía Turgot entre la filosofía de la historia y su elogio de la religión en II Progresso e la Storia in A. R. J. Turgot (17461761). Venecia/Padua, 1974, pág. 45-63. Ni Jean-Pierre CLÉMENT (Las lecturas de Jovellanos. Ensayo de reconstitución de su biblioteca. Oviedo, 1980) ni Francisco AGUILAR PIÑAL (La biblioteca de Jovellanos, 1775. Madrid, 1984) indican que el Tableau fuera lédo por Jovellanos, pero en la obra de éste se detecta cierta influencia del autor francés.

12 aSi algo sobre la tierra merece el nombre de felicidad es aquella interna satisfacción, aquel íntimo sentimiento moral que resulta del enpleo de nuestras facultades en la indagación de la verdad y en la práctica de la virtud (G. M. de JOVELLANOS, Oración sobre la necesidad, pág. 334 a). 
ropa hiciese tributario al mundo y que reciba en sí todas las verdades y virtudes que existen en él? J. C. conoció las inclinaciones humanas y fue su médico, no su cómplice. En su ley les puso un freno y opuso un dique. Quiso que los hombres fuesen perfectos, no a la manera de Arístides y Catón en cuya virtud había tanta liga de imperfección y vicio, sino por decirlo asi a la de Dios, que se conforma con las leyes naturales.

(...) El monoteísmo, la monogamia y la monarquía, fundadas sobre la unidad, desterraron el politeísmo, la poligamia y la policracia $\star^{13}$.

Los límites de la ética pre-cristiana se ponen de manifiesto al considerar el concepto de «virtud» imperante en la Antigüedad clásica. Lo que los filósofos griegos y los moralistas romanos llamaron evirtud* no escapaba de las concradicciones sociales de la época a la que pertenecían. Sin duda, «aquella moral purísima» que profesaban perseguía «la paz, el orden, la virtud», y rechazaba los "males y desórdenes". Pero 10 pudo acabar, ni en la teoría ni en la práctica, con los principios constitutivos de la «polis», la República o el Imperio. Fpicteto, Platón, Cicerón, Séneca y Marco Aurelio -contirúa Jovellanos- elaboraron una doctrina de las virtudes morales que contribuyó a mejorar la conducta pública y privada de los ciudadanos". Sin embargo, cuando proponían una norma de comportamiento adecuada a las circunstancias, todos ellos se mostraban incapaces de superar las lacras sociales que acompañaron a la civilización clásica. Por ejemplo, la esclavitud:

* Lus escritus de las antiguus filásofos y la conducta de los antiguos pueblus acreditan hasta qué punto habían perdido de vista [las] obligaciones naturales. Si de una parte establecieron la esclavitud y violaron en ella todos los derechos de la humanidad, de otra, no menos inhumanos, miraban cono sinónimos los nombres de extranjero y enemigo. De aquí nació aquella política destructora cuyos proyectos de engrandecimiento y vanagloria se levantaron sobre la ruina de cuanto estaba fuera de su círculo. La fuerza y el fraude fueron sus medios, sus instrumentos la muerte y la desolación, y una dominación sin límites, y por lo comín tan funesta a los usurpardores como a los subyugados, su objeto y último fin. De aquí también aquella vergonzosa rivalidad de intereses ya políticos ya mercantiles que armó unas naciones contra otras ... Tal es la suma de la historia ... de las sabias repúblicas de Crecia y Roma ${ }^{15}$.

Cuantas veces enumera Jovellanos los vicios de las constituciones antiguas (cualesquiera que fuesen sus formas de gobierno), otras tantas alude a la escla-

1. AHN, Consejos, leg. 49.657, n." 13, Siete popeles de apuntes autógrafos literarios de Jovellanos recogidos por orden de S. M. en sa rechusión de Palma de Mallorca.

It G. M. de JOVELLANOS, Memoria sobre la educación públice n Thatade ténico-práctico de enseñaza (1802), en BAE T. XLVI, pág. '260a-b.

15 Fiul. pág. $253 \mathrm{~b}$. 
vitud, la guerra y el desprecio al trabajo. Ello explicaría el que aun las doctrinas morales mejor orientadas, como la de Cicerón, no llegasen nunca hasta "el» hombre, es decir, no reconocieran en la mera condición humana, anterior a la condición de ciudadano, un principio de igualdad natural susceptible de perfección ${ }^{16}$. La ciencia jurídica de los magistrados romanos construía sus elementos teóricos del derecho natural sobre la base de un modelo de hombre público limitado y deficiente. Moralistas y magistrados acertaban al colocar la felicidad humana en el ejercicio de la virtud, pero se equivocaban a la hora de determinar el objeto de ésta. La aparición de Cristo ("dicha del género humano») ${ }^{17}$ muestra a la Humanidad el fin último al que debe aspirar la verdadera ética: el Ser Supremo.

«Es, pues, claro que toda moral será vana, que no coloque el sumo bien en el Supremo Criador de todas las cosas, y el último fin del hombre en el cumplimiento de su ley, de esta ley de amor, cifrada en dos artículos tan sencillos como sublimes; primero, amor al Supremo Autor de todas las cosas como el único centro de la verdadera felicidad; segundo, amor a nosotros y a nuestros semejantes, como criaturas suyas ... En el cumplimiento de esta ley se contiene la perfección del hombre natural, civil y religioso, y la suma de la moral natural, política y religiosas ${ }^{18}$.

El Cristianismo incorpora a la "moral universal» los valores de paz, fraternidad y leal colaboración entre las naciones. Esta «dulce y divina religión» resume los ideales ecuménicos y pacifistas de la utopía ilustrada del progreso:

«Quisiera que [los] hijos [de la nación española], preciándose de ser españoles y católicos, no se olvidasen jamás de que son hombres; por lo mismo que su imperio se extiende por todo el ámbito del globo, quisiera que mirasen como hermanos a cuantos viven sobre él. Quisiera, en fin, que sirviendo fielmente a su patria, no perdieser jamás de vista el vínculo que los une a toda su especie, y que a su perfección y felicidad deben concurrir a una todos los pueblos y todos los hombress ${ }^{19}$.

La "ley de amor» que enlaza a todos los pueblos y a todos los hombres destruye las barreras psicológicas del sectarismo y de la intolerancia. La catolici-

16 El reproche de JOVELLANOS /Carta a José de Vargas Ponce de 11-XII-1799, en OOCC T. III, n. ${ }^{\circ}$ 1.253, pág. 492; Reflexiones sobre la prosperidad pública-178?-, en BAE T. LXXXVII, pág. 413b) es común a la cultura ilustrada. Sirva como ejemplo el Bosquejo de un cuadro histórico de los progresos del espíritu humano (1793) de CONDORCET (Madrid, 1980, pág. 122).

17 G. M. de JOVELLANOS, Memoria sobre la educación pública, pág. $260 \mathrm{~b}$.

18 Ibid., pág. 253a; en el mismo sentido, Reflexiones sobre la instrucción pública (1796), en José Miguel CASO, El pensamiento pedngógico de Jovellanos y su Real Instituto Asturiano. Oviedo, 1980, pág. 50.

12 G. M. de JOVELLANOS, Memoria sobre la educación pública, pág. 253b. 
dad, convertida ya en cosmopolitismo, deviene moral universal. Al examinar la religión como una fuerza espiritual de civilización ${ }^{20}$, Jovellanos, al tiempo que evidencia su parentesco ideológico con otros ilustrados europeos ${ }^{21}$, se sitúa en la posición idónea para evaluar desde un punto de vista moral el papel histórico representado por la Iglesia en la historia.

A sus ojos la Edad Media se presente como un paréntesis desgraciado en la historia de Europa:

"iAh, separemos la vista de una época tan funesta para la humanidad, como vergonzosa a la sabiduríal ¿Qué nos presenta lá historia de diez siglos sino violencias e injusticias, guerra y destrucción, horror y calamidad? „Oh, siglos de ignorancia y superstición! jSiglos de ambición y de ruina, y de infarnia y de llanto para el género humano! La sabiduría os recordará siempre con exécración y la humanidad llorará perpetuamente vuestra memoria ${ }^{22}$.

La alianza de la kambición» feudal con la "superstición» religiosa es una constante de los «tiempos oscuros». No se trata tan sólo de que el poder jurisdiccional y temporal de la Iglesia creciera en exceso ${ }^{23}$, sino que además ese poder estaba al servicio de intereses particulares mezquinos: «lit nobluza y los ecte-

20 Fin Jovellanos el concepto de acivilización s comporta ur valor histórico posilivo, lo (que: mo es obstículo para que eritiquc la cortupción moral de algumos pueblos civilizados. Por cso, mide el rrado de civilización de un peís no tanto por el progreso que ha conseguido en el cultivo de las ciencias, como por el nive] de instrucción pública rjuc ha alcarrzado. Ver, a este respecto, su $/ n$ fruelucción a uti discurso (1796), en BAE I XXXVII, pág. 13a, pto. 37.

El campo semántico dẹ término xcivilización enlaza en la cultura ilustratla con el de aprogreso» y se halla desprovisto de connotaciones despectivas n irŕnicas. Warner KRALSSS, aSobre el destino español de la palabra franeesa "civilisation" en el siglo XVIIl». En BHi, n. 3-4, jul.-dic.. 1967, pág. 436-440. Iosé Autortio MARAVALL, "La palabra "civilizacióo" y su sentido en el siglo XVIII». En Actus det Quinto Congreso Internacional de Hispanistas. Burdeos, 1977, T. I, pág. 79104. José ESCOBAR, "Civilizar", "civilizaবlo" y "civilización": una polémica de 1763». En Actas del Séptimo Congreso de la Asociación Internacional de Hispanistus. Roma, 1982, T. I, pág. 419. 427. ID, "Más sobre los orígenes de "civilizar" y "cjvilización" en la España del siglo XVIIl». En NRFH, T. XXXIII (1984), pág. 88-114

21 Así, aparte de Turgot, Montesquieu on Letres Mersunes (apud Claudio SIGNORILE, op.

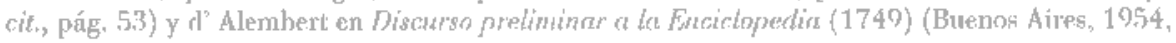
púg. 23-24).

22 G. M. de JOVELLANOS, Oración inatgural del Jnstitufo Asturiano (7-1-1794), en BAE T. XI_VI, pág. $319 \mathrm{a}$.

23 En el Discurso rie ingreso en la Rert Acatemia de in Historia (14-II-1780) afiuma JoveJlauns que en la España visigoda «ereció ilimitadamente el influjo de los obispos en los negocios públicos' (en BAET. XLVI, páp. '201b). Aunque aquí citamos por la ed. de la BAE, conviene cotejar' el texto con la copia manuscrita que se conserva en la R. Academia de la Historia (ARÁl, lib. 9. 20-5,5945, ff. 332 r-376r), ya que en otros pasajes del Discurso se ohservan variantes de importancia. Hay ed. de Caso González en Obras en prosa, Martrid, Castalia, 1976, pág. 71-102. 
siásticos eran igualmente interesados en su independencia y en la opresión del pueblo» ${ }^{24}$. Esta dominación inicua se ejercía tanto en la esfera política como en la económica. En el Informe sobre la ley agraria Jovellanos se apresura a aclarar que con su crítica a la amortización eclesiástica intenta únicamente contribuir al bien público; por eso, retrata a los religiosos «como propietarios» ${ }^{25}$. En calidad de tales, los miembros de la Iglesia amortizaron inmensas zonas de cultivo y provocaron serios daños a la agricultura española. Su conducta egoísta (su «codicia») empezó violando la propia legislación dictada en aquella época y terminó consumiendo los recursos del pueblo. Por otro lado, la Iglesia utilizó en su beneficio la propiedad de los fieles, pues hizo pasar por sacrificio de expiación las donaciones de propiedad libre a $" \operatorname{manos}$ muertas ${ }^{26}$. En un texto tan medido y "político» como el Elogio de Carlos III Jovellanos no vacila en censurar severamente la función histórica que desempeñó la Iglesia en nuestra Edad Media: «La religión, enviada desde el Cielo a ilustrar y consolar al hombre, [fue] forzada por el interés a entristecerle y eludirle ${ }^{27}$. No obstante, frente al planteamiento anticlerical de ilustrados como Condorcet, Jovellanos sigue creyendo en el potencial civilizatorio de la Iglesia y, por supuesto, en el carácter humanitario del Cristianismo ${ }^{28}$. La crítica de la institución no pone nunca en tela de juicio los fundamentos morales del Evangelio. La denuncia que formula contra ella se basa precisamente en haberse desviado, por interés y codicia, de los postulados de justicia y hermandad que proclama el mensaje evangélico. De aquí proviene su atracción por la Iglesia primitiva, en la que ve realizada la doctrina de Cristo $^{29}$.

Dos fueron los factores que cambiaron definitivamente el panorama medieval: el crecimiento de las ciudades y la acción de la Monarquía en favor del progreso. Al terminar con la «anarquía feudal», la Corona estrecha los lazos de unión civil entre los súbditos y, al conceder franquicias y libertades a los cen-

24 Ibid., pág. 295b.

25 G. M. de JOVELLANOS, Informe sobre la ley agraria (1795), en BAE T. L, pág. 102a.

Ibid., pág. 102a-b.

${ }_{27}$ G. M. de JOVELLANOS, Elogio de Carlos III (8-XI-1788), en BAE T. XLVI, pág. 312b. Un breve comentario al Elogio de Jovellanos a cargo del prof. José Miguel CASO puede encontrarse en: Ilustración y Neoclasicismo. Tomo IV de la Historia y crítica de la Literatura Española (al cuidado de Francisco Rico). Barcelona, 1983, pág. 419-421.

2a Siguiendo a Gibbon, Condorcet siente, por el contrario, un profundo desprecio por el cristianismo primitivo, «aquel azote que iba a precipitar [1a] caída del Imperio Romano» (Bosquejo, pág. 140-141). Lógicamente Jovellanos opina quel autor de Decline and Fall a es preocupado contra la religión` (Diario V, 13-II-1794, en BAE T. LXXXV, p. 150a).

29 Véanse al respecto el Elogio de Carlos 11 , pág. $314 a$, y la Oración inaugural del Instituto, pág. 319b). 
tros urbanos, fomenta el desarrollo de las "artes de la paz ${ }^{30}$. En las naciones más avanzadas protege las ciencias aplicadas. El arranque de la modernidad parece abrir una etapa de concordia y prosperidad. Pero es una simple apariencia, porque -en opinión de Jovellanos- el respaldo del poder a las ciencias acabará revelándose interesado. Si promueve el estudio de la naturaleza es por razones de seguridad interna y por afán de conquista:

[Los gobiernos] a ... conocieron que la firmeza de los Estados ya no se derivaba tanto de la virtud y el valor, cuanto del número y riqueza de sus miembros; comocieron que se apoyaba principalmente en ayuel arte iturtífero que inventó la ambición, y en la ingeniosa disciplina y en las horrendas armas que tan cruelmente perfeccionó y multiplicó; conocieron, en fin, que este poder funesto no se compraba ye sino a fuerza de oro; que si los pueblos no eran ricos, no podían ser libres y dichosos; y que levantado sobre la tierra este idolo eru preciso esperar de la sabiduría los únicos dones que podian aplacarlo. ${ }^{31}$.

La guerra, de nuevo, se erige en la suprema razón política de los Estados. Pero en esta ocasión lo hace a una escala desconocida, no sólo por la perfección técnica del ammamento y la extensión geográlica de los conflictos, sino en especial por constituir la pieza medular de la política económica de las nuevas Monarquías ${ }^{32}$. Lo que debería ser un factor de progreso (el comercio) se transfor-

30 El sentido peyorativo rgue adquiere el adjetivo afeudał" en el pensamiento histórico-políuco de Jovelíanos ųueda perfectamente zeflejado en; el Discurso de ingreso en la Real Acudemia de la Historia (BAE T. XLVY, pág. 292b y 296b), cl Informe sobre el fomento de la marinct mercante le $20-1 \mathrm{X}-1784$ (BAE'L, pág, 21a), la Oración inatgural del lnstituto Asturiano (BAE XLVI, pág. $319 \mathrm{~b}$ ), el Infome sobre la ley agraria (BAE L, rota 28 de pág. 137b) y la Carta a Curlos González de Posada de 1-VI-1796 (00CC L. III, n." 918. pág. 227). El fortalecimiento de las ciudades como fuctor de liberación, en Discurso de ingreso BAE T. XLVI. pág. 297a) y Memoria para el ame-

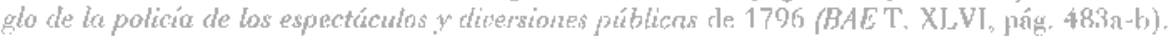
Por último, la contsiclesarión del poder numárguico como clemento de progreso se halla expresta en el Discurso de ingreso (pág. 294b, 295b-296a, 296b-297a). Aunque en todos estos textos Jovella-

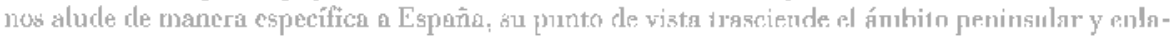
za con los plantcamientos que tefenthía Williant ROBERTSON on el vol. I de su nuagra obra The

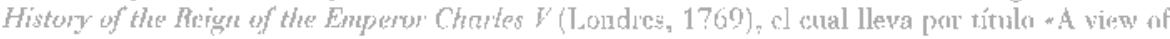
the progress of surirty in Europe, from the subversion of the Reman limpire wo the heginning of the Sixteenth Ciestury* (pág. 1-394). Dirha ubra aparece citada en la Memoria para el arreglo de lo

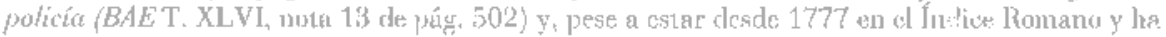

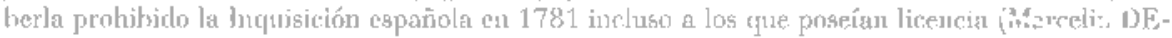
FOURNEAUX, Inquisición y censurt de thros en la España del siglo XWH. Madrid, 1973, pág. 241), cra sobradamente conocicla por Jovellanos.

"G. M. de JOVLLLANOS. Oracion inatgunit det Instituto, pág. 319ls.

32 Éste era, en efecto, uno de los postulados básicos del mercantilismo del siglo XVII. Sentarto el principio de que «nadie gana lo rue otro no pierdes, el fistado desarrollaba una política dirigista on ol interior (reglameniarión del comercin y do la industria) y de aperurd de nuevos uner-

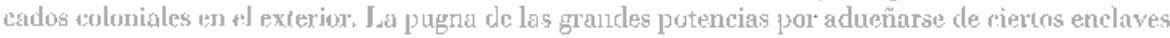


ma en principio de discordia. Jovellanos observa que la expansión comercial de los Estados tiende a incrementar los gastos militares y, por lo tanto, obliga a endurecer la fiscalidad sobre las clases productivas. La ambigüedad del progreso económico estriba en que el libre desenvolvimiento de las actividades lucrativas colapsa su mismo avance. Cuando Jovellanos califica de rilusorio este sistema (el «comercial state», como lo denominaba Adam Ferguson) ${ }^{93}$, no insinúa el problema de la desigualdad entre las clases, sino que alude al proceso de pauperización de las economías familiares desde una óptica fiscal. Inicia entonces una vía de reflexión ético-política que discurre por la senda del posibilismo reformista ${ }^{3+}$. Puesto que esa «nueva política es a una terrible necesidad», dice en la Oración inaugural del Instituto Asturiano, tratemos de conciliarla con la dicha de los «ciudadanos*:

* Cuando la fuerza pública no puede establecerse ya sino sobre el superfluo de las fortunas privadas, ¿qué deberá buscar el gobierno más justo sino el aumento de las fortunas privadas, para hacer más fime la seguridad y más respetable la fuerza pública? $x^{2 \pi}$.

Conviene adoptar ma política econónica que incremente las fortunas particulares. Medidas como la desamortización eclesiástica, la remoción de barreras conerciales interiores, la libertad de exportación, la ampliación del merca* do laboral o la libertad de comercio de granos apuntan en esa dirección ${ }^{3 t}$. Al

"vitales" para sus economias propiciaba los enfrentamientos amados. Sin embargo, con la expresión «nucva política» Jovellanos parece apuntar más allá de las prácticas mercantilistas. Su critica va dirigida probablemente a toda forma de expansión conercial realizada con violencia, cualcuiera que sea la política cconómica que la justifique. En sus escritos abundan las condenas del imperialismo britáraco: Diario HI, 3-VIII-1795 (BAAE T. LXXXV, pág, 315b); Calya a Francisco Sacavedrut

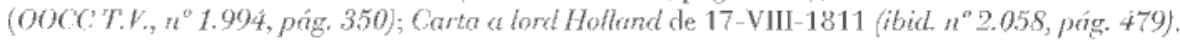

3. G, M. de JOVELLANOS, Reflexiones sobre la prosperidat püblica, en BAET. LXXXVII, pág. 414a. Adam FERGUSON, op. cit., pág. 27.

34 En este punto la filosofía política de Jovellanos se asemeja bastante a la de lierguson. El escocés reconoce la naturaleza contraclictoria del progreso naterial y, tejos de intentar combatir la

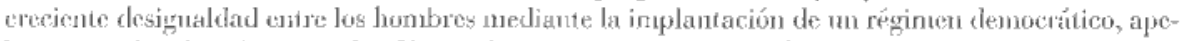
la como snlución a la avirut política de una clase dirigente seformarlora que debe destruscar a una élite corrompida y ćmica. Pero la coincirłencia en el diagnóstico y en el remedio gencral no ha de ascureces el hecho, lisióricamente fundammul, re que las estrucuras socio-conónicas cuyos ispectos positivos rlesean salvaguardar Jovellanos y Ferguson no 500 ecjuiparahles. Sus respectivos postulados icóncos, al reterirse a proresos distintos (estancamiento tardofendal de un Estado absolutista, consolidación política de la buequesía mn una dinámica de csecimiento econóntico sostenido), adquicren una significación social completamente diversa.

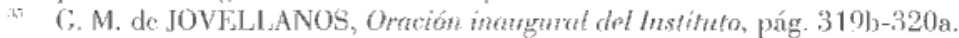

: En relación con estas medidas: Infonme sobre ln tey agrarie (BAE T, I, pág. 108-117); Informe solure el libre ejerricio de las artes (9-XJ-1785) BAE T. I, pág. 33-35), 1puntes pan uni memoria, (s.f.) (BAET. L, púg. 50-5.3). 
mismo tiempo, las autoridades deben fomentar la instrucción pública, sobre todo en lo que atañe a la enseñanza técnica y científica. Un programa económico de esta naturaleza no cuestiona los presupuestos morales de aquel sistema «ilusorio». Jovellanos es plenamente consciente:

* Es preciso decirlo de una vez y repetirlo a cara descubierta: sin costumbres no podrá esperar jamás ningún Estádo ventajas permanentes. La virtud no es sólo el fundamento de la felicidad del hombre, sino también de la de los Estados. Un Erario opulento, un ejército numeroso, una marina formidable no son las más ciertas señales de la prosperidad de una Monarquía. ¡Cuántas veces se han visto estas ventajas unidas a un gobierno injusto y opresivo! ¡Cuántas sc ha gloriado de ellas un pueblo corrompido y esclavo jCuántas esta aparente prosperidad ha conducido a la destrusción y a la ruina de los más grandes imperios! $s^{37}$.

No hay que sacar conclusiones precipitadas tras la lectura de este fragmento. Las revoluciones de los imperios no se evocan en él con el propósito de entonar un canto de alabanza al progreso material y espiritual que conduce inexorablemente a los grandes logros revolucionarios de Estados Tnidos y Francia. cuyos habitantes contemplan derribados a sus pies los fulsos ídolos de la tiranía, de formáa análogá a como el conde de Volney meditaba en medio de las ruinas de Palmira acerca de las causas que destruyeron las antiguas civilizaciones de Oriente ${ }^{3 \theta}$. I als virtudes que torman verdadera la prosperidad «aparente» son, scgún Jovellanos, mucho menos subversivas, más respetuosas, en fin, de un orden social que sólo debe ser «mejorado» por quienes se hallan oncendidos de "amor público»:

*Pero, ¿acaso la prosperidad está cifrada en la riqueza? „No se estimarán en nada las calidades morales en una sociedad? No tendrán influjo en la felicidad de los individuos y en la fuerza de los Estarlos? (...) Ja virtud y el valor deben contarse entre los elementos de la prosperidad social. Sin ellas toda riqueza es escasa, todo poder es débil. Sin actividad ni laboriosidad, sin frugalidad y parsimonia, sin lealtad y buena fe, sin probidad personal y amor público; en una palabra, sin virtud y sin costumbres, ningún Estado puede prosperar, ninguno subsistir. Sin ellas el poder más colosal se vendrá a tierta, la gloria más brillante se disipará en el humo»*3.

Por otra parte, Jovellanos no piensa -como Rousseau-que el crecimiento

37 G. M. de JOVELLANOS, Discurso pronunciado en la Matritense son motion de la distribueión de premios de hiludus (16-VII-1785), en BAE T, L, pág. 32b.

эв Sobre la lectura radical y revolucionaria que se hizo en la España del siglo XIX de la obra de Volıey, ver Demetrio CASTRO, «Los ideólogos en España: la recepción de Destutc de Tracy y de Volney». En EHS, n. ${ }^{\circ} 36-37$, enero-jumio 1986, pág. 340-342.

39 G. M. de JOVELLANOS, Memoria sobre la educación pública, en BAE T. XLVI, pág. 231b. 
económico de los Estados mercantiles represente un freno para el progreso moral de los pueblos. En este punto comparte la opinión de Hume:

«Es ... innegable que la multiplicación de los hombres engendra nuevas pasiones; que su asociación aumenta el fuego y la actividad de ellas; que del fomento de la industria debe nacer precisamente el comercio, del comercio la riqueza, y de la riqueza el lujo, enemigo y corrompedor de las costumbres. Sea, pues, un problema digno de la especulación de los filósofos saber si un cuerpo político debe renunciar a todas las ventajas que son incompatibles con la conservación de las puras y primitivas costumbres de un pueblo, o si cuando trata de aumentar la población por el único medio que ofrece la economía, esto es, aumentando los medios de subsistir, debe prescindir de tales inconvenientes. Pero, entre tanto, oigamos nosotros la voz de la humanidad y aun de la religión, que nos dicen que el cuidar de que los hombres se multipliquen, vivan y no perezcan, es el primero de todos los preceptos ${ }^{* 0}$.

Se trata de evitar que esa cadena degenerativa que va creando el Estado moderno se forje sin trabas. Eliminar los primeros eslabones, porque pueden pervertir las costumbres, y asımir un modelo de crecimiento económico alternativo, equivale a renunciar de antemano a todas las ventajas de la vida en sociedad. El dilema entre pureza moral y pasión económica lo plantea Jovellanos recordando una edad de oro de las costumbres que parece situar cronológica y espacialmente en los inicios de las civilizaciones griega y romana:

«Pero, ¡ał, quién podrá revocar aquella inocente edad que pasó como un relámpago para no aparecer más sobre la tierra! La ambición la desterró para siempre de su superficie; la ambición, que, levantando su trono sobre el de la virtud, todo lo trastocó, todo lo corrompió, todo, hasta los objetos de la sabiduría, que parecían inmutables como ella. Un general frenesí que difundió por todas partes y que infundió en todos los corazones, hizo a los hombres poner su gloria en la muerte y la desolación. Desde entonces la fuerza triunfó de la virtud, y la ignorancia de la sabiduría. Así la sabia Grecia, ennoblecida con la santidad de Cimón y de Sócrates, pereció a manos del grosero Mummio; y así también la prudente Roma, a quien engrandecieron más las virtudes de Régulo y Catón que sus sangrientos triunfos, cedió al furor del pueblo insipiente y bárbaro, que restableció sobre la tierra el imperio de la ignorancias"1.

La condena de la «ambición» se realiza desde el reconocimiento explícito de la fugacidad de la «virtud * original, una virtud que desapareció "para siem-

+1) G. M. de JOVEl_LANOS, VII Carta a Ponz (1794-1796), en BAE T. L, pág. 297b; igualmente, Introducción a un discurso, en BAE T. LXXXVII, pág. 13a, pto. 38, y Memoria sobre la educación pública, en BAE T. XLV1, pág. 231b-232a.

"G. M. de JOVELLANOS, Oración inaugural del Instituto, pág. 319a, 
pre» de la faz de la tierra. No estamos, sin embargo, ante el diagnóstico pesimista de un misántropo. Si bien es cierto que la ambición está en la base del «despotismo feudal» y de la moderna política «ilusoria», también lo es que gracias a ella han aumentado los saberes y las comodidades materiales. Por eso, la moral social que propone Jovellanos no se ocupa del «homo economicus»-que debe actuar con plena libertad de movimientos-, sino del hombre cuya socialización no está determinada por el afán de lucro. En la nota restrictiva de esta moral reside la fuerza de su programa ético:

«... se descubre en la historia que la legislación, cuidanda de envanecer a los hombres, o valientes o ricos, jamás se cuidó de hacerlos buenos; ... que si cuidó mucho de inspirarles aquellas virtudes que convenian a sus sistemas y a la elevación cle ánimo y al amor público y a la sumisión y laboriosidad, todas las demás fueron excluidas u olvidadas en su plan.

Las teyes, a lat verdad, persiguieron el crimen; pero ninguna premió la virtud ni condujo a ella. Desde entonces no buho más que virtudes negativas (...); no se trató de prevenir, sino de castigar, evitar los delitas, y como en medio de esta indiferencia moral debían nacer y fomentarse todas las pasiones, la inmoralidad cubrió la tierra» ${ }^{* 2}$.

La regeneración moral se presenta como algo que compete en exclusiva a la autoridad política. Bastaría enseñar a los pueblos aquellas «virtudes positivas" para que, al instante, las practicasen:

*La instrucción descubre al hombre todas sus relaciones y todas las obligaciones que nacen de ellas; entonces es cuando, haciéndole amarlas y disponiéndole a cumplirlas, le hacen sentir en la práctica de la virtud aquel estado inefable de paz y de contento interior que beatifican, por así decirlo, su existencia y constituyen su verdadera felicidad ${ }^{43}$.

Al enlazar de esta manera los valores sociales de cláse con la instrucción, el pensamiento ético de Jovellanos se desliza insensiblemente por la pendiente que conduce la consciencia crítica del presente a la apulugíd de un disposilivo de control "pedagógico» sobre el conjunto de la sociedad. Decir que «no hay especie de verdadera felicidad sobre la tierra que no se derive de las ideas y sentimientos morales de los hombres" ${ }^{*}$, implica legitimar la intervención del Estado, bajo la forma de "espíritu de ilustración", en la valoración de las

"2 C. M. de JOVELLASNOS, Reflexientes sobre ka prospendad pribica, en BAET: I XXXVII, pág. 414 a-b. El desnuido de la ética en los programas docentes, cn Memoria sobue le checacion piebliceat, pág. 2511\%.

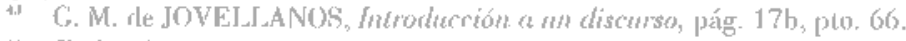

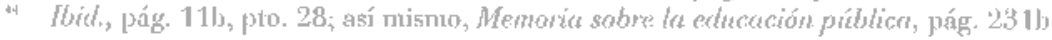


capacidades volitivas de los súbditos. Esta concepción de la felicidad particular llega al extremo de identificar el cumplimiento de las obligaciones sociales de cada estamento con "la verdadera felicidad" ${ }^{45}$.

La historia moral del género humano - tal y como la presenta Jovellanosencierra ante todo una serie de enseñanzas políticas. La Antigüedad clásica, la Edad Media y la modenidad proporcionan elementos de juicio para comprender el presente. La primera ofrece un ideal de patriotismo asociado a la "virtus», junto a un poco recomendable desprecio por las clases inferiores y las artes mecánicas. Nada aprovechable contiene la segunda. Borrando las virtudes cívicas, la "anarquía" se adueña de las naciones y la superstición cubre con su negro manto todas las inquietudes. En los albores de la Edad Moderna los científicos rescatan al hombre de su incuria cultural y aceleran el progreso de los conocimientos útiles. El poder político apoya sus trabajos, pero lo hace con fines militares antes que humanistas. Las grandes verdades del Cristianismo, mientras tanto, operan en la capa más profunda de los corazones humanos sin poder convertirse en los resortes éticos de su praxis. La «llustración», al fin, cumplirá sus preceptos tratando de situar al hombre -a todos los hombres- en el centro de sus preocupaciones. Para ello es preciso asegurar la unión civil de los habitantes del país sobre bases más sólidas que las que soportaron las «constituciones» antiguas. Además de garantizar derechos y libertades, la legislación ha de permitir el crecimiento económico. Deben cesar, por otro lado, tanto la insubordinación de los estamentos privilegiados a la Corona, como la perpetua enemistad de los Estados entre sí. La nobleza, el clero y las clases pudientes de origen plebeyo tienen que asumir de forma responsable las funciones rectoras que les corresponden. Sólo la paz hace crecer la prosperidad económica y promueve la felicidad pública; sólo la concordia produce csa comunicación de ideas en que descansa el progreso del espírita humano.

Con la historia moral Jovellanos termina dando un diagnóstico de su tiempo mucho más optimista de lo que, en principio, cabría imaginar. El punto de vista que adopta para esbozar su gran cuadro moral es el mismo con el que enfoca la política reformista del Estado y, por consiguicnte, todo lo que tiene de lícida crítica de un mundo en crisis lo tiene también de ilimitada esperanza en la capacidad de reforma del "espíritu de ilustración», transfigurado así en remedio universal.

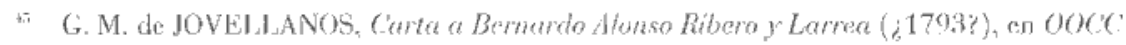
T. Il, 1." 442, pág. 598; Informe sobre la ley agruine, en BAE T. L, pág. 90a. 